\title{
Artes visuais e identidade em espaços multiculturais não hegemônicos:
}

Madalena Zaccara

\section{Resumo}

O projeto intitulado Artes Visuais e Multiculturalidade: conexões, está em fase de desenvolvimento e tem como objetivo traçar relações entre a produção artística contemporânea de Recife, capital de Pernambuco e outros centros não hegemônicos comparando-a com o universo globalizado das artes visuais focando a possibilidade de preservação de uma política identitária. No trabalho que propomos pretendemos expor alguns resultados obtidos tomando como referência duas obras de dois artistas: um canadense e um pernambucano. São eles: Isidorio Cavalcanti, de Recife, e Terrance Houle um ameríndio de Calgary. Através dos dois queremos estabelecer a sobrevivência da identidade e de um olhar político nos dois espaços sociais.

Palavras chave: artes visuais, política, identidade.

\section{Abstract}

The project titled Visual Arts and Multiculturalism: Connections is in development phase and has as goal to trace relationships between the contemporary artistic production of Recife, capital of Pernambuco and another non-hegemonic centers comparing it with the globalized universe of the visual arts, focusing in the possibility of preservation of an identity politics. In the work that we propose, we intend to expose some results obtained taking as reference two works of two artists: a canadian and one from Pernambuco. They are: Isidorio Cavalcanti, from Recife, and Terrance Houle, native of Calgary. Through both we want to establish the survival of the political identity and look in both social space.

Keywords: visual arts, politics, identity 


\section{0 sagrado coração de Isidorio: o poder através da memória}

Pernambuco caracteriza-se por ter sido berço do Movimento Regionalista, liderado pelo sociólogo Gilberto Freyre, bem como um dos primeiros espaços sociais brasileiros a abrigar a modernidade no sentido de atualização das linguagens artísticas nacionais com as vanguardas européias. Aparentemente contraditória essa condição ainda aparece na produção artística contemporânea juntando linguagens atuais a uma tradição estética e renovando, dessa forma, nesse momento pós-colonialista, seu vocabulário sem, porém perder o vínculo com a sua memória.

O Movimento Regionalista iniciou-se em 1924. Naquele momento, o resgate do Nordeste, enquanto região e cultura, segundo Durval Muniz de Albuquerque Junior “dá-se à medida que o dispositivo da nacionalidade e a formação discursiva nacional-popular colocam como necessidade o apagamento das diferenças regionais e a sua integração no nacional” (ALBUQUERQUE JUNIOR, Durval Muniz, 1999:79). Ou seja: quando uma região agrária viu-se ameaçada pela dominação do sudeste industrializado, urbano e hegemônico.

Essa plataforma regionalista foi reafirmada, na década de 70, através do Movimento Armorial sob a liderança do escritor Ariano Suassuna. A proposta armorial era a defesa de uma arte erudita a partir do popular na tentativa de combater a descaracterização da cultura brasileira e da nordestina em particular.

Ambas as propostas comungam a idéia de um mundo que tenta sobreviver. As opiniões sobre a ideologia do movimento armorial, por exemplo, se dividem. Para alguns teóricos como o já citado Durval Muniz (2009:77) ela teria como objetivo manter o poder da aristocracia rural em declínio e se voltaria "para a construção do Nordeste como um espaço tradicional». Para outros, tomando-se como referência seu principal teórico vivo, Ariano Suassuna (1970 apud NEWTON JUNIOR, Carlos Newton, s/d) ela despertaria as pessoas "para verem ao seu redor».

A introdução de um vocabulário artístico contemporâneo no Estado, principalmente em Recife, sua capital e cidade economicamente mais desenvolvida, deu-se a partir dos anos 90. Para essa atualização. Contribuíram algumas instituições oficiais e os muitos coletivos de artistas atuantes na cidade. Eles atualizaram a produção artística local bem como criaram um público interessado em novas linguagens artísticas.

Publico e mercado, entretanto, existem a partir de uma situação periférica em relação aos grandes centros hegemônicos. Para situarmos esse conceito de periferia (em geografia e política), nós nos apoiaremos nas palavras da teórica quebecoise Rose-Marie Arbour (1999:9): 
La circulation libre des cultures est une illusion. Tout en partageant des valeurs artistiques et esthétiques semblables. La confusion est impossible entre les pouvoirs qui son ceux des pays périphériques et ceux des pays dominants en matière artistique et culturelle(...) dans le sens de géographie territoriale mais aussi culturelle et artistique, dans le contexte de domination politique d 'un pays par un autre, ou d'une région par une autre. ${ }^{1}$

É nesse contexto de periferia que uma nova geração de artistas emerge. A tradição alia-se então à experimentação como processo, gerando discursos que reúnem uma informação estética globalizada a uma identidade regional. Segundo a teórica da arte educação Ana Mae Barbosa (2006):

Os artistas do Nordeste continuaram a desenvolver sua própria cultura visual, rejeitando ou assimilando as correntes internacionais com autonomia pessoal e não por indução, construindo uma trama de diversidade visual incomum, com qualidade, apontando para um pós-colonialismo muito mais definido que nas regiões dominadoras do país .

Dessa geração faz parte o artista plástico Isidorio Cavalcanti, nascido em Gameleira, uma pequena cidade do interior do estado de Pernambuco. Apesar de autodidata, no sentido da ausência de um conhecimento acadêmico sistematizado, Elias Isidorio Cavalcanti buscou sempre informações teóricas, principalmente sobre a produção artística contemporânea. Desde o início de sua trajetória, que data do começo dos anos 90, observa-se a participação do artista em cursos diversificados, como ouvinte, na Universidade Federal de Pernambuco.

Isidorio desenvolve as mais variadas técnicas e meios além dos diversificados materiais em suas instalações ou ações performáticas. Sua obra se articula em torno da apropriação. São construções (onde ele usa o espaço ou o próprio corpo) alimentando todo um conjunto de associações possíveis para o espectador. Nelas, ele expõe, costura e modifica a matéria em uma forma alusiva a sua reconquista.

Trabalhando sempre com materiais inusitados, quase sempre descartados, fazer arte para ele é além de um exercício constante, uma diversão. $\mathrm{O}$ artista não quer ou espera que seu trabalho convença as pessoas, apenas que ele desperte novas percepções e novas sensações.

Isidorio quer representar "os mundos internos das emoções das disposições e do intelecto" segundo afirma (2001) como também busca ,de acordo com suas palavras (2001), "novos modos de descrever o mundo cambiante que o rodeia". O "outro" seu 
parceiro (e ele mesmo) é o objetivo para o qual o artista captura o banal, o cotidiano e o (re) configura a partir de seus saberes regionais e locais.

Sua experiência com artes visuais teve início quando, desempregado, decidiu fazer um curso de Desenho de Modelo Vivo com Abelardo da Hora, na Associação dos Artistas Plásticos situada, então, na Rua da Aurora, Recife. Lá, entrou em contato com outros artistas visuais e conheceu a técnica de resina. Nela, Izidório encontrou uma liberdade que não lhe era dada na pintura convencional: foi o início de sua busca constante por novos materiais.

Nesse processo, no fim dos anos 90, ele passou a reutilizar o papel dos outdoors para representar os perigos da sedução da publicidade aplicando, sobre esse suporte, técnicas de pintura variadas. A partir desse momento, em sua trajetória, os materiais ligados ao seu cotidiano e à sua cultura definem a sua poética.

A linguagem da perfomance pode dar vida a múltiplos personagens e questionamentos através da imersão do ator e do espectador em uma dimensão multisensorial e interativa. $\mathrm{O}$ espectador descobre-se como parte da ação e é afetado pelas historias de mundos, contadas através dessa relação entre obra e fruidor. Descontroi-se, assim, a condição de observador, própria do teatro; estabelecendo-se uma condição de parceria e cumplicidade. É nessa forma de expressão que embarca Isidorio no inicio do novo século. Esse é outro recurso explorado por Isidorio em seu apelo aos sentidos do observador.

Em 2006 ele apresenta ao público pernambucano e paulista a performance Sagrado Coração de Isidorio (fig. 1). Em Recife na sede do coletivo Branco do Olho e em São Paulo na Mostra Internacional de Performances, promovida pela Galeria Vermelho com curadoria de Daniela Labra.

$\mathrm{Na}$ ação, ele coloca um coração de boi pregado em cima do seu peito,

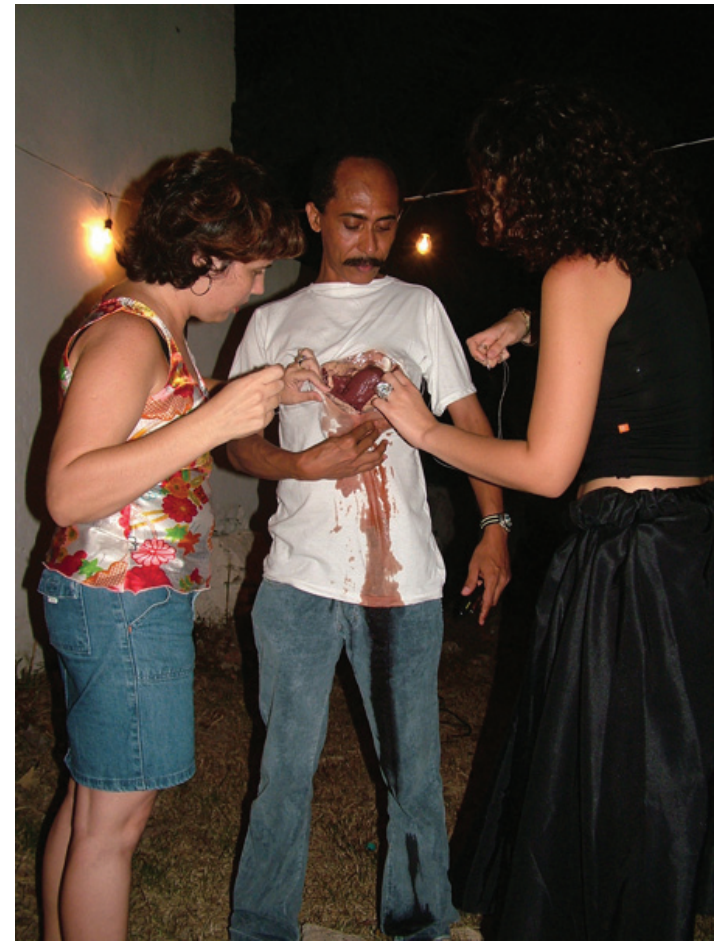

Fig. 1. Isidorio Cavalcanti. Sagrado Coração de lsidorio.

Performance. Recife. 2006. 
corta-o com uma faca e deixa o sangue escorrer sobre a camisa branca que usa para a ocasião. Em seguida, o artista convoca o público presente a costurar a ferida, costurar seu coração. A reação do público varia da atração a repulsa. A performance inspira-se sensivelmente nas estampas encontradas nos lares mais humildes do Nordeste brasileiro onde a iconografia católica/barroca de Jesus o apresenta com o coração à mostra cercado por uma coroa de espinhos e sangrando. A imagem está associada ao inconsciente coletivo do público e faz referência ao imaginário do próprio artista propondo-se, por sua vez, a mais uma vez provocar a memória e os sentidos do "outro", espectador. Fazendo referência indireta à cultura nordestina o artista faz política. Não uma política panfletária, mas aquela que busca a sobrevivência da identidade na voragem contemporânea do modelo único globalizado e globalizante.

\section{Terrance Houle: jogando com os clichês.}

Dentro da imagem internacional que o Canadá projeta no mundo e em um momento onde as tensões provocadas pelos efeitos homogeneizadores da globalização se tornam cada vez mais visíveis, os "invisíveis" autóctones encontram ainda poucos canais de expressão. O Canadá, como o Brasil, traz em si essa carga multicultural e, portanto, funciona como pólo catalisador das referidas tensões. O universo das artes visuais não se constitui em uma exceção nessa conjuntura.

Entretanto, alguns guerreiros dos novos tempos, artistas que buscam suas raízes e sua memória indígena como fonte de inspiração e lutas, fazem com que as fronteiras se tornem mais visíveis e menos demarcadas. Eles tomam posição política em exposições que falam de direitos das comunidades locais como La loi sur les Indiens revisitée, (2009) e em grandes eventos como é foi caso da Bienal de Havana (Resistência e integração na era da globalização, 2009).

Segundo Guy Sioui Durand (2010:4):

Les indiens sont de retour sur les scènes géopolitiques, environnementales, artistiques et spirituelles! À observer de plus près ce contexte où se nouent les tensions entre globalisation et altermondialisme, on retrace constamment la présence d 'artistes authoctones. ${ }^{2}$

As fronteiras se movem. Os dois mundos (a comunidade e a cidade) se tornam comuns e os questionamentos também. Por outro lado, segundo Hall (2006:32) "encontramos aqui a figura do indivíduo, exilado ou alienado, colocado contra o pano-de-fundo da multidão ou da metrópole anônima e impessoal.» Nessa metrópole cinzenta e homogênea onde os indivíduos e as identidades se confundem fazer política é chamar também a atenção para costumes e culturas que se diluem sob os nossos olhos. 
É nesse território novo, fragmentado, anônimo e mutante que trabalha sua identidade o artista canadense ameríndio Terrance Houle: o índio que brinca de índio em seus trabalhos performáticos. Nascido em Calgary, em 1975, ele utiliza, de maneira performática, certos clichês associados às culturas autóctones. Aqueles que determinam e exigem um comportamento padrão esperado.

Na obra Urban Indian, 2006, o artista incorpora (em colaboração com o fotógrafo Jerusha Brown que registra a ação) um personagem vestido com uma roupa cerimonial ameríndia que passeia pela cidade e faz as ações cotidianas de um cidadão comum. Pela manhã ele se paramenta com os trajes rituais, beija a esposa e o filho na porta de uma casa típica de subúrbio canadense (fig. 2) e segue para o trabalho em um escritório padrão. Telefone em uma das mãos e atendendo e carimbando documentos ele se deixa fotografar pelo cúmplice.

Na sagrada hora do almoço canadense o Índio urbano come na cafeteria da esquina lendo seu jornal como qualquer cidadão branco "civilizado". Depois do trabalho ele para em um supermercado (fig. 3) sempre vestido em sua roupa tradicional e finalmente retorna a casa onde toma um banho de banheira como todo mundo.

As fotos que documentam a ação performática são de uma profunda ironia. $\mathrm{O}$ ator joga com dois estereótipos: o índio da comunidade e o cidadão comum, pai de família trabalhador americano. Ao mesmo tempo em que une os dois universos ele mostra o quanto estão separados no que diz respeito às tradições culturais das tribos e o cotidiano do mundo moderno. Brincando com os dois modelos ele faz uma caricatura de ambos.

Ele reinvidica o direito à banalidade das ações corriqueiras brancas, integradas, cosmopolitas, mas também o de encarnar sem vergonha a sua cultura sem se importar com o contexto e sem temer o estranhamento causado. Ele parece dizer, com sua ação, que não é porque é um autóctone e que tem sua própria cultura que ele não pode trabalhar em um escritório, comprar um pão ou beijar sua mulher ritualisticamente como o fazem os brancos.

Houle questiona essa visão estática que temos do ameríndio e de todas as comunidades autóctones do planeta cujas identidades foram usurpadas pelos brancos conquistadores. 


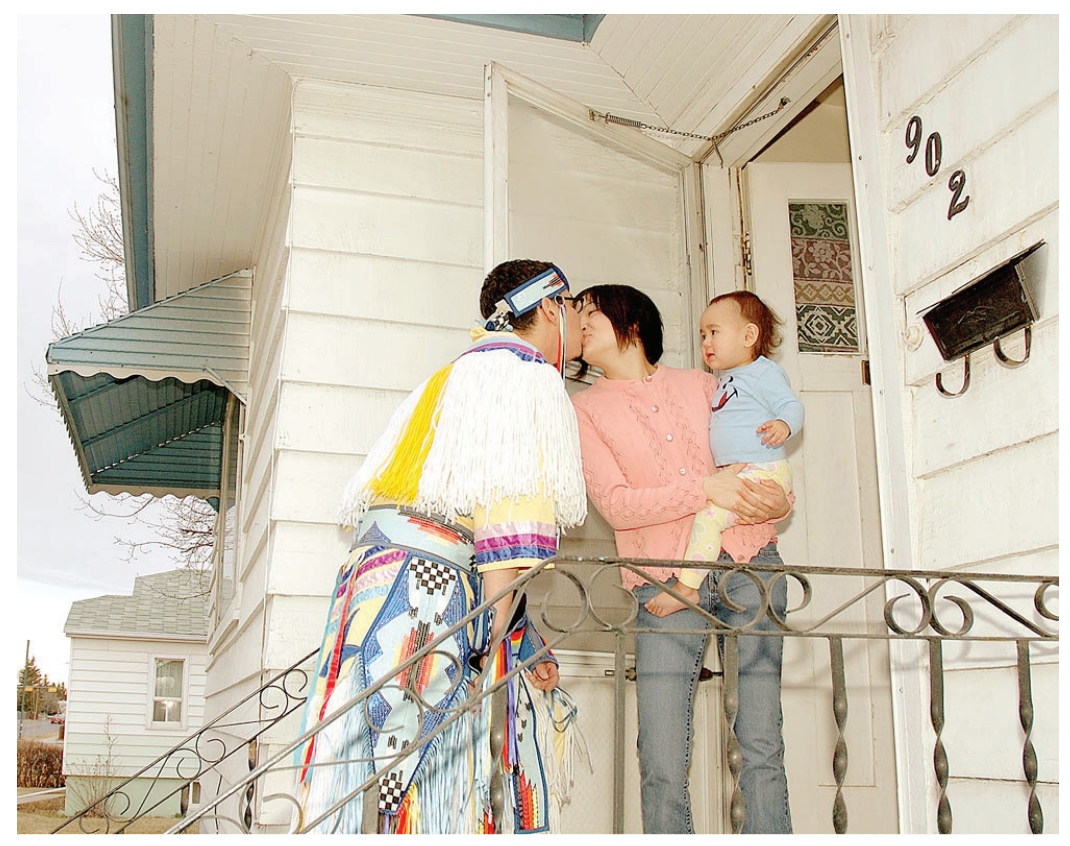

Fig. 2.

Terrance Houle.

Urbain Indien.

Performance. 2006

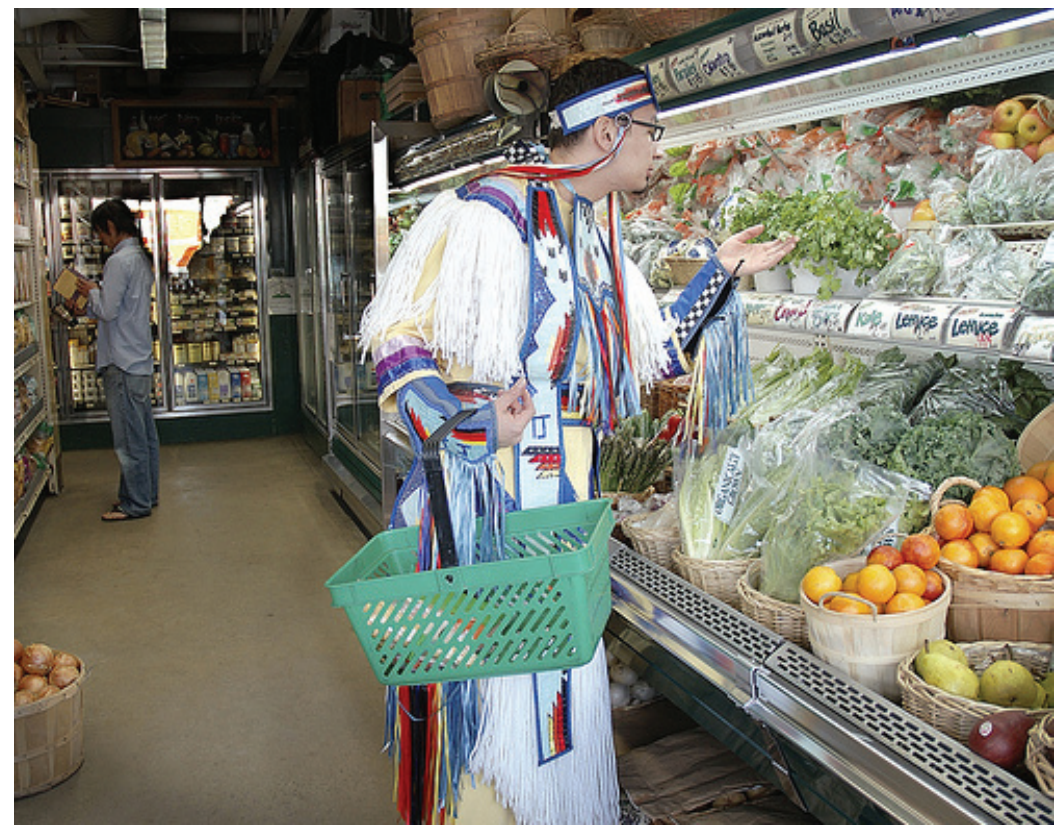

Fig. 3.

Terrance Houle.

Urbain Indien.

Performance. 2006 
Suas imagens são uma crítica evidente à sociedade capitalista que ela sabota através da ação de jogar na cara do espectador/cúmplice a banalidade da vida cotidiana que vem substituir sob a pena da marginalização, os costumes tribais dos primeiros habitantes da terra.

As roupas coloridas ancestrais do artista/performer jogam com o cinzento uniforme da vida do colonizador. O espectador passa tecnicamente a se questionar. Não somos todos uns estereótipos ambulantes obedecendo a convenções de representação?

O aparente humor da ação traz uma política de resistência pela identidade como bandeira. Sem panfletos ele oferece a oportunidade de que o público se sinta atingido sem ser agredido. Ele (o humor) possui poder de imunidade. A ação de Hole se passa, portanto, quase que como uma brincadeira. Um índio que brinca de índio não pode ser mais que uma piada. Mas, através desta ação, ele sabota as regras fingindo segui-las e cria um espaço para a identidade autóctone canadense.

\section{Estratégias políticas em busca da preservação de uma identidade.}

Em uma sociedade cada vez mais hierarquizada, controlada, desigual, hedonista e submissa aos interesses da rentabilidade mercantil parece distante o pensamento livre ou uma arte transformadora que seria um instrumento de educação e politização. Uma ética dentro da estética.

O artista é a memória de uma cultura a partir da premissa de que sua obra reflete o pessoal e o social. Ao lado da construção de um mundo próprio ele pode ir mais longe e interferir no coletivo a partir da fascinação que ele produz no espectador. Esse "xamanismo" está na origem da influência que a arte exerce sobre as pessoas.

A obra de arte, portanto, vista por esse ângulo, é um espaço de manifestação da cultura, da história e mais enfaticamente da verdade dessa realidade vivida, sentida e compartilhada, Sendo assim ela foi (e é ainda) uma arma política, pois, mesmo entrecruzada com outros universos culturais ela (através da memória, preservada) não é neutra e o artista é o agente catalisador dessa construção que incide na possibilidade da transformação ou de preservação do social.

Particularizando a memória como instrumento de luta política em um mundo que a destrói, podemos visualizar uma interpretação da ação política da arte no pós - modernismo. Para Cheetham (1992:21) "La memoire, avec ses inflexions de sens évanescentes et portant particulières est 1 ' histoire das une culture postmoderne" ${ }^{3}$.Preservar a memória seria, portanto, politizar a história. 
Entretanto, esse viés político particular à arte na contemporaneidade não implica na intenção de promover uma mobilização quer no campo social, quer no estético. Ela não implica em militância, o que não caracteriza sua inexistência. O engajamento político é circunscrito a critérios pessoais, extremamente diversificados, e compreende uma coerência entre os valores mais profundos do artista e suas relações com o mundo. Ele prioriza o indivíduo bem como suas maneiras particulares de operacionalização. Ele aparece na escolha das formas, na temática, nas atitudes e mesmo na escolha do público alvo.

Ele (o engajamento) também se faz presente em uma procura no sentido de incluir o outro aproximando o público da sua memória pessoal e da implicação de sua arte com a vida real. Esse público é conduzido através da sua percepção para um maior conhecimento de si mesmo.

Nesse contexto o trabalho se Isidorio Cavalcanti e o de Terrance Houle (produtos de culturas aparentemente diversas, mas que comungam o contexto periférico anteriormente definido) propõem a mesma visão humanista de uma idéia de resistência onde a política é estetizada e o artista é um agente eficaz contra a amnésia coletiva que adormece nossa sociedade pós-moderna. Recife e Quebec, através de seus artistas, mantêm uma consciência política afirmando uma rejeição aos símbolos máximos de opressão vivenciados pelo artista enquanto criador e cidadão.

\section{Notas}

1. A circulação livre das culturas é uma ilusão. Embora compartilhando valores artísticos e estéticos semelhantes. A confusão torna-se impossível entre o poder dos países periféricos e os dos países dominantes em matéria artística e cultural (...) no sentido geográfico, territorial, mas também cultural e artístico dentro de um contexto de dominação política de um país pelo outro ou de uma região por outra.(tradução do autor)

2. Os índios estão de volta na cena geográfica, ambiental, artística e espiritual!Observando de mais perto esse contexto onde se processam as tensões entre a globalização e a antiglobalização nós encontramos constantemente a presença de artistas autóctones. (tradução do autor)

3. A memória com suas inflexões de sentido evanescente e, portanto, particular é a história das culturas pós-modernas. (tradução do autor). 


\section{Referências bibliográficas}

ALBUQUERQUE JUNIOR, Durval Muniz. A Invenção do Nordeste e outras artes. Recife: Massangana/São Paulo: Cortez, 1999.p.79.

ARBOUR Rose- Marie. L'art qui nous est contemporain.Montreal : Editons Artextes, 1999

BARBOSA, Ana Mae Artes Plásticas no Nordeste disponível em

http://www.scielo.br/pdf/ea/v11n29/v11n29a13.pdf

CAVANI, Julio. Os sons da arte contemporânea. Diário de Pernambuco. Recife: 21 de março de 2006.

Correio Brasiliense. Brasília, novembro de 2006.

Correio da Paraíba. João Pessoa, 16 de março de 2000.

CARANI, Marie. Des lieux de memoire : identité et culture modernes au Québec 19301960.Ottawa : Les presses de l'université d 'Ottawa, 1995

CHETETHAM, Mark. A. La memoire postmoderne : essai sur l'art canadienne contemporain. Montréal : Liber, 1992.

DANTO, Arthur C. Após o fim da tarde: a arte contemporânea e os limites da história. São Paulo: EDUSP, 2006.

Diário de Pernambuco. Recife, 21 de março de 2006.

Diário de Pernambuco. Recife, 7 de novembro de 2001.

Jornal do Commercio. Recife, 24 de agosto de 2004.

DURAND. Guy Sioui. Resistance : chocs et résilience in Inter Art Actuel. Québec : Les éditions Intervention, 2009, n.102. pp.22-25.

DURAND. Marc. Histoire du Québec. Paris : Imago, 2002

FOURNIER, Marcel. Les générations d'artistes. Québec : Institut québécois de recherche sur la culture, 1986. 
HALL, Stuart. A identidade cultural na pós-modernidade. Rio de Janeiro DP\&A Editora, 2006.

HESRCOVICI, Alain 2001, apud SILVA, Sergio Salustiano in Identidades culturais na pós-modernidade: Um estudo da cultura de massa através do grupo Casaca in http:// www.bocc.ubi.pt/pag/silva-sergio-salustiano-identidades-culturais.html

LAMY, Jonathan. Terrance Houle : 1 'Indien qui joue à 1 'indien qui joue à 1 'indien in Inter Art Actuel. Quebec : Les editions du Lieu ,2009/2010.

NEWTON JUNIOR, Carlos in Movimento Armorial: regional e universal. Recife: Maga Multimídia.

ZACCARA, Madalena. Investigações sobre a arte contemporânea a partir da poética de Isidorio Cavalcanti in O artista pernambucano contemporâneo e o ensino da arte. Recife: Editora da Universidade Federal de Pernambuco, 2011. 